Note

\section{Identification of the Microorganism Which Produces Insecticidal Indole Alkaloids, Okaramines A and B}

\author{
Hideo Hayashi, Kunio TakiUchi, \\ Sawao Murao and Motoo Arai \\ Department of Agricultural Chemistry, \\ College of Agriculture, \\ University of Osaka Prefecture, \\ Sakai, Osaka 591, Japan \\ Received April 5, 1991
}

Various insecticidal compounds have been found among the metabolites of microorganisms, but only a few compounds such as tetranactin ${ }^{1)}$ are used. During the investigation of the insecticidal compounds produced by microbes, we found that an isolate, Streptomyces sp. AH-4, from a soil sample produced insecticidal compounds, physostigmine and $N^{8}$-norphysostigmine. ${ }^{2)}$ We further screened fungi for insecticides using okara (the insoluble residue of soybeans) as a medium, and successfully got a strain, AK-40, from a soil sample. This strain, when grown on okara, showed strong insecticidal activity on silkworms upon oral administration. Active compounds named

Table I. Cultural and Physiological Characteristics of Strain AK-40

Colony (growth at $25^{\circ} \mathrm{C}$ after 7 days on Czapek agar) size diameter of $3.7-3.9 \mathrm{~cm}$

texture floccose (flocculent)

color greyish green, partly orange white reverse side color pale yellow-brownish red

Colony (growth at $25^{\circ} \mathrm{C}$ after 7 days on Czapek-yeast extract agar)

size diameter of $4.8-5.1 \mathrm{~cm}$

texture velvety, radiate furrows

color dull green, partly orange grey

reverse side color light brown, partly dull red

Colony (growth at $25^{\circ} \mathrm{C}$ after 7 days on Malt agar)

size

diameter of $3.1-3.9 \mathrm{~cm}$

texture velvety

color dull green

reverse side color greyish yellow

Temperature range for growth

$$
14-37^{\circ} \mathrm{C}
$$

optimum at $26-32^{\circ} \mathrm{C}$

$\mathrm{pH}$ range for growth

optimum at $3.0-4.5$ okaramine A and okaramine B were isolated, and their structures were determined. ${ }^{3-5)}$ In this paper we report the identification of the fungus producing okaramines, and we also describe cultural media for the production of okaramines.

The isolated strain AK-40 was assigned to Penicillium, since it produced the penicillus as the reproductive structure.

Cultural and physiological characteristics of the strain $\mathrm{AK}-40$ are listed in Table I.

Morphological characteristics are as follows: conidiophores arise either directly from substratum or as branches of aerial hyphae, stipes $150-600 \mu \mathrm{m}$ long, rough walled, bearing regular to irregular verticils of metulae; penicilli predominantly biverticillate, extended-order; metulae widely extended, $2-4$ in verticils, $10-20 \times 2.5-3.5$ $\mu \mathrm{m}$, rough walled; phialides ampulliform, $5-8$ per metula, $7-10 \times 2.5-3.0 \mu \mathrm{m}$; conidia subglobose or ellipsoidal, $3.0-3.5 \times 2.0-3.0 \mu \mathrm{m}$, slightly rough walled, borne in disordered chains.

Strain AK-40 agreed well with the descriptions and illustrations of Penicillium simplicissimum (Oudem.) Thom provided by Raper and Thom, ${ }^{6)}$ Pitt, $^{7)}$ and Ramirez. ${ }^{87}$ Therefore, $P$. simplicissimum IFO 5762 and AK-40 were compared. Since strain AK-40 showed good agreement with IFO 5762, AK-40 was identified as $P$. simplicissimum (Oudem.) Thom.

To identify the best medium for the production of okaramines, various natural media such as wheat bran,

Table II. EFfects of Media ON THE InseCticidal ACTIVITY SHOWN By $P$. simplisiccimum AK-40

\begin{tabular}{lccc}
\hline & \multicolumn{3}{c}{ Mortality rate (\%) } \\
\cline { 2 - 4 } & \multicolumn{3}{c}{ Amount of sample added to one gram of diet } \\
\cline { 2 - 4 } & $1 \mathrm{mg}$ & $10 \mathrm{mg}$ & $100 \mathrm{mg}^{*}$ \\
\hline Okara & $50 \%$ & $100 \%$ & $100 \%$ \\
Cotton seed cake & 0 & 0 & 100 \\
Rape cake & 0 & 23 & 100 \\
Wheat bran & 0 & 0 & 93 \\
Soybean & 0 & 17 & 100 \\
Rice & 0 & 0 & 0 \\
Potato & 0 & 0 & 50 \\
Sweet potato & 0 & 0 & 20 \\
Orange peel & 0 & 20 & 100
\end{tabular}

* Values are expressed in terms of weights equivalent to media. Before autoclaving, every medium was treated as follows: to $100 \mathrm{~g}$ of cotton seed cake and rape cake $40 \mathrm{ml}$ of water was added; to $10 \mathrm{~g}$ of wheat bran $60 \mathrm{ml}$ of water was added; soybean and rice were soaked in water overnight and the water was removed by decantation; to $100 \mathrm{~g}$ of bread without crust $20 \mathrm{ml}$ of water was added; potato or sweet potato was cut into around $1-\mathrm{cm}$ cubes. 


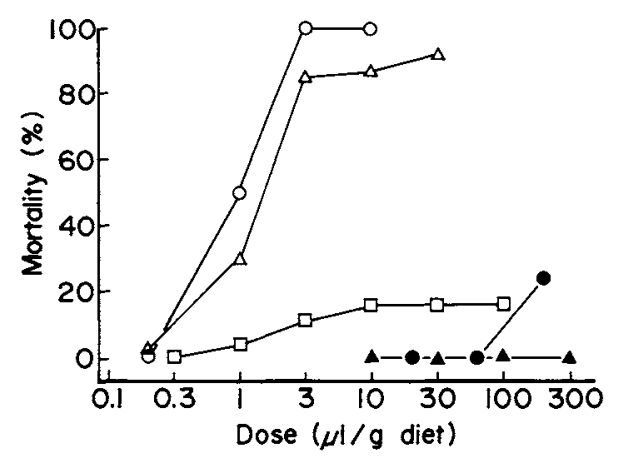

Fig. 1. Insecticidal Activity Shown by Strains Belonging to $P$. simplicissimum.

Each strain was inoculated into $100 \mathrm{~g}$ of okara. After cultivation at $25^{\circ} \mathrm{C}$ for two weeks, media and mycelia were extracted with acetone. The acetone extract was adjusted to a volume of $100 \mathrm{ml}$, and then the insecticidal activity was tested.

Symbols: - - - AK-40;-- A-, IFO 5762;- $\square-$, AHU 8065; - $\triangle-$, AHU 8402; - - MF-24.

rape cake, and potato were examined in a solid state culture. This strain showed a good growth on all media except rice and bread, and the insecticidal activity varied with media. Table II clearly showes that okara was the best medium for the production of insecticides. Rape cake, soybean, and orange peel were moderate media, but other media showed a poor productivity of insecticides. AK- 40 produced okaramine A and okaramine B when grown on cotton seed cake, wheat bran, and soybean (data not shown).

Okara is a waste material left when tofu (bean curd) is made from soybeans, but the okara had better productivity of the insecticides than the soybeans. The difference may be derived from that in the physical conditions of these two materials.
Since we had an interest in the unique structures of okaramines, we tried to find if okaramines or similar compounds were produced by other strains (IFO 5762, AHU 8065, AHU 8402, and MF-24 of P. simplicissimum). Figure 1 demonstrates that IFO 5762 and AHU 8065 had either weak or no activity on silkworms, and that AHU 8402 showed activity almost equivalent to AK-40. MF24 , which was isolated in our laboratory, also showed a weak insecticidal activity, but it caused convulsions, a tremor-like syndrome, in the larvae. Data on the active constituents of AHU 8402 and the convulsive principle of MF-24 will be published elsewhere.

Acknowledgment. The authors express their thanks to Dr. Takao, Professor of Hokkaido University, for his generous supply of $P$. simplicissimum AHU 8402 and AHU 8065 .

\section{References}

1) K. Ando, Y. Murakami and T. Nawata, J. Antibiot., 24A, 418 (1971).

2) S. Murao and H. Hayashi, Agric. Biol. Chem., 50, 523 (1986).

3) S. Murao, H. Hayashi, K. Takiuchi and M. Arai, Agric. Biol. Chem., 52, 885 (1988).

4) H. Hayashi, K. Takiuchi, S. Murao and M. Arai, Agric. Biol. Chem., 52, 2131 (1988).

5) H. Hayashi, K. Takiuchi, S. Murao and M. Arai, Agric. Biol. Chem., 53, 461 (1989).

6) K. B. Raper and C. Thom, "A Manual of the Penicillia," The Williams and Wilkins, Baltimore, 1949, p. 304

7) J. I. Pitt, "The Genus Penicillium and Its Teleomorphic States Eupenicillium and Talaromyces", Academic Press, London, 1979, p. 276.

8) C. Ramirez, "Manual and Atlas of the Penicillia," Elsevier Biomedical Press, Amsterdam, 1982, p. 246. 